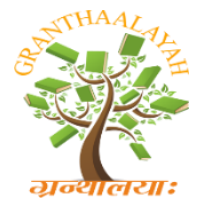

$$
\begin{gathered}
\text { INTERNATIONAL JOURNAL OF RESEARCH - } \\
\text { GRANTHAALAYAH } \\
\text { A knowledge Repository }
\end{gathered}
$$

Science

\title{
SERO PREVALENCE STUDY OF BRUCELLOSIS IN GOATS IN HAMER AND BENATSEMAY WOREDAS OF SOUTH OMO, ETHIOPIA
}

\author{
Dr.Seifu Lemma ${ }^{1}$, Dr Abeyenh Leza ${ }^{2}$, Gimete Gercha ${ }^{3}$, Alemayeh Radii 4 \\ 1, 2, 3,4 Jinka Animal Health Laboratory Centre, P.O. Box 62, Jinka Ethiopia
}

\begin{abstract}
Brucellosis is a contagious bacterial disease with worldwide importance and affects a number of animal species and human beings. Although brucellosis in domestic animals has controlled in most developed countries it remains an important public health problem in several parts of the world. But in developing countries brucellosis has both animal and public health importance (Walker, 1999; Radostitset al.,2000; Acha, and Szyfers, 2001; Tsolia et al.,2002).

Keywords: Brucellosis; Hammer; Benatsemay; CFT; RBPT; Goats.

Cite This Article: Dr.Seifu Lemma, Dr Abeyenh Leza, Gimete Gercha, and Alemayeh Radii. (2019). "SERO PREVALENCE STUDY OF BRUCELLOSIS IN GOATS IN HAMER AND BENATSEMAY WOREDAS OF SOUTH OMO, ETHIOPIA." International Journal of Research - Granthaalayah, 7(8), 166-174. 10.29121/granthaalayah.v7.i8.2019.649.
\end{abstract}

\section{Introduction}

Brucellosis occurs worldwide in domestic animals such as cattle (B.abortus), sheep (B.ovis), sheep and goats (B.melitesis), dogs (B.canis), pigs (B.suis), desert wood rats (B.neotomae) and camels due to B.aborrtus. In addition to this it occurs in wild animals (Seifert,1996).

The disease creates a serious economic problem for both the intensive and extensive livestock production systems in tropics. Abortion may lead to retained fetal membranes, metritis and long period of infertility. Infertility in turn increases the period between lactation and the intercalving period may be prolonged by several months (OIE, 1997; Radostitset al., 2000). Sterility, cull of animals due to breeding failure, endangering animal export trade of a nation, loss of man-hours and medical costs and governmental costs on research and eradication schemes (Chukwa, 1987).

In Ethiopia several investigators have established the endemicity of bovine brucellosis in different parts of the country and the available information on brucellosis clearly showed that the disease is endemic and wide spread with significant economic and public health importance (Bayeleygn, 1989; Endrias, 1989; Tekelayeet al., 1989; Abay, 1999; Abeje, 1994; Yilkal, 1998; Taddesse, 2003; Abrha, 2003). 
Brucellosis is considered by WHO, FAO and OIE as one of the most wide spread zoonoses (Schelling et al., 2003). Human brucellosis is still the most common zoonotic disease worldwide with 500,000 new cases reported annually (Sascha et al., 2007). The disease causing agent Brucella is directly or indirectly transmitted from its animal reservoir to man. Human brucellosis is a flue like disease without specific signs or characteristic symptoms. Acute febrile illness undulant fever, which may progress to a more chronic form and can also produce a serious complication affecting the musculoskeletal, cardiovascular and central nervous system (OIE, 1997). The mortality in human is low but the involvement of multiple organs may be debilitating for a long time (Sascha et al.,2007).

Brucellosis is usually an occupational disease occurring in veterinarians, farmers, stock inspectors, abattoir workers, laboratory personnel and butchers (Acha, and Szyfers, 2001). Brucellosis is hyper endemic in Saudi Arabia, with more than 8000 human cases reported per year. This is due to the consumption of fresh unpastuerized milk from sheep, goats and camels is a traditional practice, and in Saudi Arabia it is considered the main source of brucellosis in persons. Offering fresh milk to visitors is a sign of hospitality in the culture and boiling is believed to remove the goodness from the milk (Memish, 2001). B. abortus and B. suis infections usually affect occupational groups while B.melitensis infection occur more frequently than the other types in the general population and are known to cause more sever clinical pathological effect (Acha, and Szyfers, 2001).

In many developing countries brucellosis is believed to be prevalent in a wide range of animal species. Information on the distribution, prevalence and the impact of the disease on public health and animal production are not properly studied and documented (Kudi, 1997). In Ethiopia, generally, prevalence of brucellosis was found to be high in the more intensive management systems like dairy farms and ranches than in the extensively managed animals. Seroprevalence of bovine brucellosis in Ethiopia was reported to vary from $0.14 \%$ to $38.7 \%$ depending on the intensive or extensive cattle management systems. On the other hand, information on the epidemiology of brucellosis in animals and humans in the study area i.e. south omo, hamer and benatsemayworeda is none.

Therefore, to overcome scarcity of food of animal origin and attain food self-sufficiency, the major animal diseases including brucellosis should be studied, controlled and if possible eradicated. This will not only increase the productivity of animals but also have a positive impact to reduce the disease incidence in humans.

Therefore, the objectives of the work will be:

- To determine the prevalence and distribution of brucellosis in small ruminants

- To investigate potential risk factors associated with brucellosis

- To obtain baseline data on the current brucellosis in the study area

- To advise measures to be taken to control and prevent brucellosis. 


\section{Materials and Methods}

\section{Description of the Study Area}

The survey area was found in South Omo zone, Hamer and BenaTsemayworedas that were located, respectively, 100 and $42 \mathrm{kms}$ far away from jinka. The woredas were semi pastoralistand $75 \%$ of its population depend on livestock production.

\section{Location, Topography, Elevation and Climate}

The geographical location of the survey site is $40 .{ }^{\circ} 50$ ' to $50 .{ }^{\circ} 47^{\prime}$ north latitude and $36 .^{\circ} 15$ to $36 .^{\circ} 75^{\prime}$ east longitude and its elevation is $<500$ to 2000 m.a.s.l. The woredas bordered north with Konso, south Dasenech and Kenya, east Oromiya -Borena zone and west with Dabube Arii, Male woreda and Mago national park.

The annual rainfall ranges from $400 \mathrm{~mm}$ to $1500 \mathrm{~mm}$ per annum. The rainfall in the area was bimodal falling between the months March and April over 75\% of rainfall was received while 25 $\%$ was been in the month of Augustto November.

\section{Study Animals}

The study was been carried on goats, and goatherds owned by pastoralists was been included in the study animals. The study animals was been comprised of local konsoguji goat.

The true representatives of the study population was been selected by combination of simple random and cluster sampling methods. Based on this, blood sample was been collected from a total 604goats.

\section{Study Protocol}

A cross sectional study was been conducted using serological (RBPT and CFT) and questionnaire survey from August 2018 to October 2018 in the Hamer and Benatsemayworedas of south Omo. The serological survey was been intended to determine the individual animal, herd and within herd prevalence and also to identify individual animal risk factors associated with seropositivity to brucellosis semi pastoralist of the woredas. Also, questionnaire was been administered at the same time to assess the role of different management related farm or herd level risk factors influencing brucellosis seroprevalece.

\section{Sample Size Determination}

\section{Goats}

Random sampling for sheep and goats was been used using the formula

$\mathrm{Ts}=(1.96)^{2 *} \mathrm{P} \exp (1-\mathrm{Pexp})$

$\mathrm{d}^{2}$

Where:

Pexp = expected prevalence

$\mathrm{d}=$ desired absolute precision

Ts $=$ total number of animals to be sampled 
An expected prevalence of $50 \%$ and 5\%desired absolute precision was been substituted; since previous prevalence was not available, $50 \%$ was been used (Thrusfield, 2005). Accordingly the estimated sample size goats was been 384; however, to increase the precision 604 goats were been sampled.

\section{Serological Test}

Blood sample was been collected from jugular vein of each animal with no history of vaccination for brucellosis using plain vaccutainer tubes and needles. The blood samples were been identified by each individual animal and allowed to clot at room temperature. Then serum was been separated from clotted blood by centrifugation. The separated sera were been stored at $-20 \mathrm{c}^{\mathrm{o}}$ until tested by both RBPT and CFT which were important for screening and confirmatory tests respectively.

\section{Questionnaire Survey}

Randomly selected livestock owners from the semi-pastoralist production system was been interviewed using pre-tested structured questionnaire to determine management and husbandry risk factors, which were known or thought to influence the spread and maintenance of brucellosis. Productive and reproductive parameters were presumed to be affected by brucellosis was been also incorporated in the questionnaire (Annex). The respondent recall memory was been used as a data source. This result then was been compared with serological results.

\section{Data Collection and Management}

Disease conditions was been defined in general terms. At the beginning of months (August and October 2018) of the study period animal inventory, site assessment and extension system was been made to determine the actual number of animals at risk. Data (blood sample) was been collected and recorded by making regular visits to each peasant's association with in two months (August and October 2018). The samples were been arranged according to each kebele in the woreda. After collecting blood sample laboratory works proceed.

\section{Statistical Analysis}

Data obtained from both serological tests and questionnaire was been stored in Microsoft excel spreadsheet. These data then were being analyzed by descriptive statistics using SPSS 11.5 for window and analytical statistics using incorcooled STATA 10.0 software (Stata corporation, Texas, USA, 2001) programs. Animals tested positive to both RBPT and CFT serially was been said to be sero-positive. Clusters (herds) having at least one sero-positive cattle was considered being positive. The individual animal level sero-prevalence was been calculated on the basis of RBPT and CFT positive results divided by total number of animals and humans tested. Similarly, herd (clusters) level sero-prevalence was been computed as the number of clusters (herds) with at least one positive animals divided by the total number of clusters (herds) tested. The within cluster (herd) sero-prevalence was been calculated by dividing the number of positive reactors in the cluster (herd) (Thrusfield, 2005).

Questionnaire data was been expected to provide some information about the existence of brucellosis. Accordingly, the data included risk factors associated with management, husbandry, culling of frequently aborting goat, reasons for sell of breeding goat, method of disposal of fetal membrane, dry season watering and those reproductive parameters thought to be influenced by the 
disease. The results obtained from questionnaire was been compared with that of serological results.

\section{Manpower Needed for Surveillance of Brucellosis in Hamerworeda}

Dr Seifu Lemma, AtoAlemayehu Redi, W/roTayechwako,GamadeDebelo, W/ro AzalechGersu, W/ro MarenshBezabeh, W/roAynalem Demissie,AtoMaserasha Tekele and Ato Gezahegn Tesfaye.

\section{The Field Program}

The surveillance will be carried out from August 1 to October 312018. The team will be oriented about brucellosis and other works procedure by laboratory head and then they were been collected field material from the laboratory such as camera, Veterinary equipment (Syringe, needles, gloves, disinfectants, test tubes (vacutainer), cotton roll etc.) and other and travelled to Hamerworeda with woreda leader of animal and fishery production department. Also the work activity will be as follows: site assessment, extension work and blood sample collection, questionnaire survey will be conducted and laboratory examination of the collected blood sample will be done by Rose Bengal Plate Test and Complement Fixation Test. A

\section{Result}

\section{Laboratory Result}

From 604 Caprine serum sample collected serially tested by RBPT and CFT; 24 (3.97\%) and $12(1.98 \%)$ were positive for Rose Bengal Plate test (RBPT) and CFT respectively.

\section{BENATSEMAY WOREDA}

Table 1: Rose Bengal result

\begin{tabular}{|l|l|l|l|l|l|l|l|l|l|}
\hline No & Keble & $\begin{array}{c}\text { Number } \\
\text { of Goat }\end{array}$ & \multicolumn{2}{|c|}{$\begin{array}{c}\text { Rosbengal } \\
\text { Test Positive }\end{array}$} & & Prevalence & \multicolumn{2}{c|}{$\begin{array}{c}\text { Rose Bengal } \\
\text { Negative }\end{array}$} & \\
\hline & & & Female & Male & Total & \multicolumn{2}{c|}{ Female } & Total \\
\hline 1 & Sile & 53 & 0 & 1 & 1 & 1.88 & 14 & 38 & 52 \\
\hline 2 & Alduba & 47 & 0 & 2 & 2 & 4.1 & 19 & 26 & 45 \\
\hline 3 & Duma & 50 & 6 & 2 & 8 & 16 & 16 & 26 & 42 \\
\hline 4 & Luka & 50 & 1 & 0 & 1 & 2 & 18 & 32 & 50 \\
\hline 5 & Gurmma & 51 & 0 & 0 & 0 & 0 & 10 & 41 & 51 \\
\hline 6 & Kako & 50 & 1 & 1 & 2 & 2 & 11 & 37 & 48 \\
\hline & Sub total & 302 & 8 & 6 & 14 & 4.63 & 88 & 200 & 288 \\
\hline & & & & & & & & & \\
\hline 1 & ALLA & 50 & - & - & - & - & 13 & 47 & 50 \\
\hline 2 & Zalkata & 53 & 0 & 1 & 1 & 1.88 & 5 & 47 & 52 \\
\hline 3 & Shankokalma & 50 & 0 & 1 & 1 & 2 & 3 & 46 & 49 \\
\hline 4 & BASHADA & 50 & 3 & 0 & 3 & 6 & 0 & 47 & 47 \\
\hline 5 & Areya & 50 & 4 & 0 & 4 & 8 & 10 & 36 & 46 \\
\hline 6 & Dimaka zuria & 49 & 1 & 0 & 1 & 2.04 & 0 & 48 & 48 \\
\hline & Sub total & 302 & 8 & 2 & 10 & 3.3 & 21 & 271 & 292 \\
\hline & Total & 604 & 16 & 8 & 24 & 3.92 & 109 & 471 & 580 \\
\hline
\end{tabular}




\section{COMPLMENT Fixation Test Result}

Table 2: CFT in Benatsemay woreda

\begin{tabular}{|l|l|l|l|l|l|l|}
\hline No & Keble & No of Goat Sampled & \multicolumn{2}{|l|}{ Positive on CFT } & Total & Prevalence \\
\hline & & & Male & Female & & \\
\hline & Benatesmay woreda & & & & \\
\hline 1 & Aleduba & 47 & 2 & 0 & 2 & 4.2 \\
\hline 2 & Dumma & 50 & 1 & 3 & 4 & 8 \\
\hline 3 & Luka & 50 & 0 & 0 & 0 & 0 \\
\hline 4 & Gurmma & 51 & 0 & 0 & 0 & 0 \\
\hline 5 & Kako & 50 & 0 & 0 & 0 & 0 \\
\hline 6 & Sile & 53 & 0 & 0 & 0 & 0 \\
\hline & Sub total & 302 & 3 & 3 & 6 & 1.98 \\
\hline & total & 604 & & & 12 & 1.98 \\
\hline
\end{tabular}

\section{CFT test in Hammer woreda 2011 E.C}

\begin{tabular}{|l|l|l|l|l|l|l|}
\hline No & Keble & No of Goat Sampled & \multicolumn{2}{l|}{ Positive on CFT } & Total & Prevalence \% \\
\hline & & & Male & Female & & \\
\hline 1 & Dimeka & 49 & 0 & 1 & 1 & 2.04 \\
\hline 2 & Bashada & 50 & 0 & 3 & 3 & 6 \\
\hline 3 & Areya & 50 & 0 & 2 & 2 & 4 \\
\hline 4 & Alla & 50 & 0 & 0 & 0 & 0 \\
\hline 5 & Zalkata & 53 & 0 & 0 & 0 & 0 \\
\hline 6 & Shanko kalema & 50 & 0 & 0 & 0 & 0 \\
\hline & Sub total & 302 & & 6 & 6 & 1.98 \\
\hline & Total of two woredas & 604 & & & 12 & 1.98 \\
\hline
\end{tabular}

\section{Questioners Result}

The questioner was administered to a total of 32 pastoralist within 12 kebeles of two woreds, Hamer and Benatsemay. The questioner result showed that, 32/100\%/ respondent was answered about management information such as type of livestock, grazing system, type of mating and etc. $32 / 100 \% /$ of respondent were discussed the most important of shoat disease in countered in the area in the previous year, however, $6(18.75 \%)$ of them they know the disease that cause abortion while 26(81.25\%) they do not know. They know a disease characterized by abortion followed by retained placenta, yes answered 30(93.75\%) and $2(6.25 \%)$ no answered. 32 (100\%) respondent was Observed abortion on still birth in goat. In case of separation of pregnant goat during parturition yes answered $23(71.87 \%)$ and no answered $9(28.13 \%)$

Handle aborted fetus by bare hand, drinking of raw milk and blood which may main way of acquiring the disease. From house hold member's responsible person in caring small ruminant are children and females, when children come across aborted goat while keeping them, they handle by bare hand. Children and female are most risk group in house hold in acquiring brucellosis from small ruminants. 


\section{Discussion}

Small ruminants are main source of income for poor communities in developing counties. The community daily life and livelihood is dependent on animal and animal products which allow easy transmission of zoonotic disease from animal to human. Brucellosis is one of a disease which can affect health of human who has close contact with animal and feeding habit of raw animal products. As in other area, brucellosis has not been brought under control in Southern livestock, which might be due to trans-boundary animal movement, information gap about disease both in human and animal health professionals, absence of strategic plan to prevent/control brucellosis in animal and human, lack of awareness of the disease among pastoralists, farmers, and the general public( Boukary et al. 2013). The current study indicated serological evidence of brucellosis in small ruminant, information gap on existence of disease both in human and animal health professionals; and lack of community awareness about zoonotic importance of the disease.

However, tests currently used for the serological diagnosis of $B$. melitensis infections in sheep and goats were initially developed for the diagnosis of B. abortus infections in cattle. Although not formally validated for use in sheep and goats, these tests, and in particular the Rose Bengal plate agglutination test, the complement fixation test, and more recently the ELISA have been used for the serological diagnosis of brucellosisin sheep and goats. A combination of tests shows a degree of sensitivity and specificity which appears sufficient to detect infected animals. However, in Bena tes may and Hammer woredas 604 goats were tested by rose Bengal plate test and only 24 were positive while 12 positive by complement fixation test. But, there is currently no specifically validated test for the serological diagnosis of $B$. Melitensis infection in small ruminants as the tests were transferred from those used for the diagnosis of B. Abortus in cattle. It is essential that comparison trials of classical and newly developed tests are carried out to validate tests for diagnosis in sheep and goats.

This study showed that the overall sero-prevalence of small-ruminant brucellosis in Hmmer and Benatsemay woredas of South Omo zone South nation nationality state, Ethiopia was 1.98 in goat .This finding considerably similar with the study conducted by (Golo et al. 2013 ) in Borena zone, Oromia region with prevalence of 1.17 and $1.88 \%$, in sheep and goat respectively; and lower than study conducted by( Sintayehu et al. 2015) with prevalence $3.3 \%$ small ruminant brucellosis.

As this study showed, pastoralists recognize abortion in their animals but have no awareness about zoonotic importance of the disease. They consume raw milk, animal blood and eat aborted fetus, handle aborted fetus with bare hand without any protective clothing. Pastoralist's daily life is linked with livestock production and their close contact with animal and animal product is obvious. This permits spread of zoonotic diseases that are communicable from animal to human. Animals unavoidably contaminate their environment during abortion or calving with discharges which might be the source of infection to other animals while humans are often infected through contact with the infected animals, aborted materials and vaginal discharges.

\section{Conclusion}

The study revealed that brucellosis is prevalent and well-established infection among goats in the study area. Sero-prevalence of brucellosis was observed in goats. It could be concluded that the 
positive animal can be a potential risk for both animals and humans in the area. In addition, communities in study area had no awareness about zoonotic importance of the disease. This could increase risk of human brucellosis. Despite, high risk of human brucellosis exists; physicians are not considering brucellosis while diagnosing patients with suggestive clinical sign of brucellosis.

Therefore, we recommend that

1) National brucellosis control and prevention strategy should be developed and applied,

2) Community should be educated about zoonotic importance of the disease and

3) Human and animal health professionals; have to work together on zoonotic disease; like brucellosis for successful prevention and control of the disease both in human and animals

4) 4. Test should be supported one with the other, rose Bengal with CFT or ELISA for more accurate result

\section{References}

[1] Abay, B., Bayleyegn, M., Yilkal, A., Laikemariam, Y. (2000): Bovine brucellosis; seroepidemiological study in selected farms and ranches in southestern Ethiopia. Bull. Anim. Hlth. Prod. Afr. 48: 13-17.

[2] Abeje, S. (1994): Sero-epidemiological study of bovine brucellosis in and around Bahirdar. DVM Thesis, FVM AAU, Debre-Zeit, Ethiopia.

[3] Abrha,T. (2003): Brucellosis in cattle and small ruminants in selected sites of Tigray Region, North Ethiopia. DVM Thesis, FVM, AAU, Debre-Zeit, Ethiopia.

[4] Acha, P.U. and Szyfers, B. (2001): Zoonosis and Communicable Disease Common to Man and Animals. 3rd ed. Pan America Health Organization. Washington, D.C. Pp. 40-296.

[5] Bayleyegn, M. (1989): Sero-epidemiological survey of bovine brucellosis in Arisi region. DVM Thesis, FVM, AAU, Debre-Zeit, Ethiopia.

[6] Bishop, G.C., Bosman, P.P., Herr, S. (1994): Brucellosis. In: Coetzer, Thomson and Tustin (eds), Infectious Diseases of Livestock.Vol.2. Oxford Universty Press. Pp. 1053-1066.

[7] Boukary AR, Saegerman C, Abatih E, Fretin D, AlambédjiBada R, et al. (2013) Seroprevalence and potential risk factors for brucella spp. Infection in traditional cattle, sheep and goats reared in urban, periurban and rural areas of Niger. PLoS ONE 8(12): e83175.

[8] Chukwu, C.C. (1987): Brucellosis in Africa part II. The importance of animal brucellosis.Bul . Anim. Hlth. Prod. Afr. 35: 92-98.

[9] Endrias, Z. (1989): Seroprevalence study of bovine brucellosis in selected sites of Sidamo Region. DVM Thesis, FVM, AAU, Debre-Zeit, Ethiopia.

[10] Gebreyesus, M. (2001): Sero epidemiological investigation of bovine brucellosis in North Western Ethiopia (unpublished).

[11] Golo D, Mulugeta T, Mekonnen A (2013) Small ruminant brucellosis: Serological survey in Yabello District, Ethiopia. Asian Journal of Animal Sciences 7(1): 14-21

[12] Kubuafor, D.K., Awumbila, B. and Akanmori, B.D. (2000): Seroprevalence of brucellosis in cattle and humans in the Akwapim-South district of Ghana: Public health implications. Acta Tropica. 76: 45-48.

[13] AKudi, A.C., Kallo, D.J.U. and Kudi, M.C. (1997): Brucellosi in camels. Arid. Environ. 37: 413417.

[14] Memish, Z.A. (2001): Brucellosis in laboratory workers at a Saudi Arabian Hospital. Am. J. Infec. Cont. 29: 48-52.

[15] Menachem, B. (2002): Control of small ruminant brucellosis by use of Brucella melitensis Rev. 1 vaccine: laboratory aspects and field observations. Vet. Microbiol. 90: 97-519. 
[16] Mussie, H., (2005): Seroprevalence study of brucellosis in cattle and human in Bahirdar milkshed. MSc Thesis, FVM, AAU, Debre-Zeit, Ethiopia.

[17] OIE. (1997): Bovine brucellosis In: Manual of Standards for Diagnostic Tests and Vaccines. 3rd ed. O.I.E., Price.

[18] Radostits, E.D., Gay, C.C. and Inchcliff, K.W. (2002): Veterinary Medicine. Text book of the disease of cattle, sheep, pigs, goats and horses, 9th ed. New York: W.B. Sounders Company ltd. Pp. 867-882.

[19] Sascha, A.D., Philippe, L.F., Karsten, N., Isabelle,J. and Maggy, G. (2007): Evaluation brucellosis MLVA typing for human brucellosis .J. Microbiol. Meth. (in press).

[20] Schelling, E., Diguimbaye, C., Daoud, S., Nicoletti, J., Boertin, p., Tanner, M. and Zinnstag, J. (2003): Brucellosis and Q-fver seroprevalence of nomadic pastoralists and their livestock in Chad. Prev. Vet. Med. 61: 279-293.

[21] Schwabe, C.W. (1984): Human health costs of animal diseases. In: Veterinary Medicine and Human Health, Williams and Wilkins, 3rd. ed., Pp.33-35.

[22] Seifert, H.S.H. (1996): Brucellosis.In: Tropical Animal Health. 2nd ed. Kluwer Academic Publishers, London. Pp. 356-368.

[23] Sintayehu G, Melesse B, Abayneh AD, Sintayehu A, Melaku S, et al. (2015) Epidemiological survey of brucellosis in sheep and goats in selected pastoral and agro-pastoral lowlands of Ethiopia. Rev Sci Tech Off mnt Epiz 34(3).

[24] SPSS for window Release 11.5.0 (6 sep 2002)

[25] STATA Intercooled stata 7.0 (stata corp. 1984-2001, college station Texas 77845, USA.

[26] Tadesse, Y. (2003): Asurvey of brucellosis in selected areas of North Gonder Zone. DVM Thesis, FVM, AAU, Debre-Zeit, Ethiopia.

[27] Tekeleye, B., Kassali, O.B., Mugurewa, M. sholtens, R.G., Tamirat, Y (1989): The prevalence of brucellosis in indigenous cattle in central Ethiopia. Bull. Anim. Hlth. Prod. Afr. 37: 97-98.

[28] Tesfay A, Legesse H, Berhane G, 1997. Land use planning agronomy

[29] Thrusfield, M. (2005): Veterinary Epidemiology 3rd ed. London: Blackwell Science Ltd. Pp. 227247.

[30] Tsolia, M. Drakonaki, S., Messaritaki, A., Farmarakis, Th., Kostaki, M., Tsapra, H. and Karpathios, Th. (2002): Clinical features, complications and Treatment outcome of childhood brucellosis in Central Greece. J. Infec. 44: 257-262.

[31] Walker, L.R. (1999): Brucella. In Veterinary Microbiology. Dwight, C., Hirsh, D.C. and Zee, Y.C.. (ed). Blackwell Science. Pp. 196-202

[32] Yilkal, A., Bayleyegn, M., Karl-Hans, Z. and Azage, T. (1998): The epidemiology of bovine brucellosis in intra and peri-urban dairy production systems in and around Addis Ababa, Ethiopia. Trop. Anim. Hlth. Produ. 46: 217-224.

\footnotetext{
*Corresponding author.

E-mail address: workinehlemma6@ gmail.com
} 